This item was submitted to Loughborough's Research Repository by the author.

Items in Figshare are protected by copyright, with all rights reserved, unless otherwise indicated.

\title{
Holistic thermal energy modelling for full hybrid electric vehicles (HEVs)
}

PLEASE CITE THE PUBLISHED VERSION

https://doi.org/10.4271/2020-01-0151

PUBLISHER

SAE International

VERSION

AM (Accepted Manuscript)

PUBLISHER STATEMENT

This paper was accepted for publication in the journal SAE Technical Papers and the definitive published version is available at https://doi.org/10.4271/2020-01-0151.

\section{LICENCE}

CC BY-NC-ND 4.0

\section{REPOSITORY RECORD}

Fletcher, Tom, Nikolaos Kalantzis, Ahmed Ahmedov, Ruoyang Yuan, Kambiz Ebrahimi, Nilabza Dutta, and Christopher Price. 2020. "Holistic Thermal Energy Modelling for Full Hybrid Electric Vehicles (hevs)". Loughborough University. https://hdl.handle.net/2134/11865822.v1. 


\title{
Holistic Thermal Energy Modelling for Full Hybrid Electric Vehicles (HEVs)
}

\author{
Tom Fletcher ${ }^{1}$, Nikolaos Kalantzis ${ }^{1}$, Ahmed Ahmedov ${ }^{1}$, Ruoyang Yuan ${ }^{1}$, Kambiz Ebrahimi ${ }^{1}$ \\ Nilabza Dutta ${ }^{2}$, Christopher Price ${ }^{2}$ \\ ${ }^{1}$ Loughborough University, UK \\ ${ }^{2}$ Jaguar Land Rover, UK
}

\begin{abstract}
Full hybrid electric vehicles are usually defined by their capability to drive in a fully electric mode, offering the advantage that they do not produce any emissions at the point of use. This is particularly important in built up areas, where localized emissions in the form of NOx and particulate matter may worsen health issues such as respiratory disease. However, high degrees of electrification also mean that waste heat from the internal combustion engine is often not available for heating the cabin and for maintaining the temperature of the powertrain and emissions control system. If not managed properly, this can result in increased fuel consumption, exhaust emissions, and reduced electric-only range at moderately high or low ambient temperatures negating many of the benefits of the electrification. This paper describes the development of a holistic, modular vehicle model designed for development of an integrated thermal energy management strategy. The developed model utilizes advanced simulation techniques, such as co-simulation, to incorporate a high-fidelity 1D thermo-fluid model, a multi-phase HVAC model, and a multi-zone cabin model within an existing longitudinal powertrain simulation environment. It is shown that the final model is useful of detailed analysis of thermal pathways including energy losses due to powertrain warm-up at various ambient temperatures and after periods of parked time. This enables identification of sources of energy loss and inefficiency over a wide range of environmental conditions.
\end{abstract}

\section{Introduction}

The combustion of fossil fuels produces several harmful emissions including; $\mathrm{CO}_{2}, \mathrm{NO}_{\mathrm{x}}$, Particulate Matter (PM) and Hydrocarbon (HC) emissions. Worldwide transport accounted for $8.24 \mathrm{GtCO}_{2}$ in 2017 [1], representing $25 \%$ of global $\mathrm{CO}_{2}$ emissions which contribute to global warming through the greenhouse effect. $\mathrm{CO}_{2}$ (along with water) is a direct product of hydrocarbon combustion and therefore its production unavoidable for fossil fuel-based internal combustion engines. $\mathrm{CO}_{2}$ emissions can therefore only be reduced by increasing the efficiency of the powertrain. Similarly, PM and HC emissions tend to be the result of incomplete combustion and increasing the efficiency of the combustion can result in a massive reduction of these species. In contrast, however, $\mathrm{NO}_{\mathrm{x}}$ emissions tend to be caused by extremely high in-cylinder temperatures; usually occurring due to highly efficient combustion at high loads. Therefore, the objective of $\mathrm{NO}_{\mathrm{x}}$ emission reduction can often compete with that for efficient combustion in conventional vehicles. $\mathrm{NO}_{\mathrm{x}}$ emissions react with moisture and other compounds to form nitric acid vapor and other particles. These can penetrate deeply into the lungs worsening respiratory disease [2]. Although NOx emissions can travel large distances, they tend to be a localized problem in urban areas [3] due to high numbers of vehicles in a relatively small space. As a result, many cities are beginning to introduce Low Emission Zones (LEZs) and Zero Emission Zones (ZEZs) in order to combat the issue of localized transport pollution.

Battery electric vehicle (BEVs) produce no harmful emissions at their point of use, however they tend to have a limited range for their cost [4] and cannot be re-charged as quickly as a conventional vehicle [5]. This makes them ideal for purely urban usage where journey distances are typically small, speeds are low and there may be tight restrictions on emissions. However, their limited range makes them unsuitable for intra-urban journeys. Full hybrid electric vehicles (FHEVs) are characterized by the combination of internal combustion engine with a tractive electric motor and the ability to operate in electric-only mode.

FHEVs, operating in electric-only mode, also produce no emissions at the point of use and are therefore are ideal for combatting localized emissions in urban areas while still having the capability to travel large intra-urban distances when using the internal combustion engine (ICE) [6]. However, this advantage comes at the expense of both cost and complexity [7]. Whereas a conventional vehicle, or even a mild hybrid (MHEV) can use the engine to run ancillary devices such as water pumps, oil pumps, and an air-conditioning $(\mathrm{A} / \mathrm{C})$ compressor and use waste heat from combustion to heat the cabin, a FHEV requires all of these devices to be able to operate on electrical power, similar to in a BEV [8]. However, unlike a BEV, the engine is still present and can be used when available. In addition, FHEVs tend to have higher total power output than BEVs and therefore greater overall demand on the ancillaries.

In order to assess the efficiency of a FHEV as a whole, the kinetic, electrical, chemical and thermal energy should be considered concurrently. Many studies already consider a subset of these domains. In particular, there are a huge array of work [9-12] describing the optimization of the Energy Management Strategy (EMS), which typically considers the electrical, chemical and mechanical energy of a hybrid vehicle, based on assumption that the ICE is constantly at normal operating temperature. This assumption may hold for micro- and mild-hybrids, but for FHEVs it is possible that the engine may cool down significantly during extended periods of electric-only driving. This will lead to increased fuel consumption

Page 1 of 15 
and exhaust emissions when the engine is restarted due to poor combustion efficiency and higher friction at low engine temperature [13-15].

In actuality, the requirement to model the thermal energy is not limited to the ICE. The capability of a battery pack to absorb regenerated braking energy is highly dependent on its temperature $[16,17]$. By controlling power split between regenerative braking and mechanical braking depending on the battery temperature, more energy can be absorbed; increasing the efficiency of the vehicle. Equally, most EMs are able to provide short bursts of power above their continuous maximum power limit [18], therefore a control strategy which is aware of the temperature of the EM will have greater control authority to maintain the ICE in its most efficient operating region. The efficiency of the transmission is also dependent on its temperature. The viscosity of lubricating oil increases at low temperatures resulting in greater pumping and frictional losses [15,19-21]. Therefore, efficiency gains can be made by actively heating the transmission oil during warm-up using waste heat from the engine. Power losses from ancillary devices should also be considered. In particular, it has been found that cabin climate control can account for around $22 \%$ [22] of the fuel consumption of a HEV. However, due to the relatively slow system dynamics of the cabin thermal mass, efficiency gains can be made by scheduling this load appropriately based on powertrain demand [23]. Finally, the effectiveness of exhaust aftertreatment system is highly dependent on temperature, particularly that of the catalyst [24]. It has been shown that for gasoline vehicles under real-world driving conditions, the majority of $\mathrm{CO}$ and $\mathrm{HC}$ emissions occur before the catalyst reaches "light-off" temperature [25].

Due to the significance of cold start conditions on both fuel economy and emissions, passive heat losses occurring when the vehicle is stationary should also be considered as a potential means to improving efficiency. This can be achieved by through control, such as limiting fan and pump after-run or closing active vanes [26] and through passive means such as insulation of the engine [27-30].

Each of these components has a high degree of interaction with the others; it is therefore important to ensure their integration is considered from the start [31]. For example, the temperature regulation of the battery pack will affect its current absorption capability. If the cooling system and battery are designed in relative isolation, and each is designed with its own safety margins, the overall performance will be compromised. However, the integration of a number of complex interactive systems is in itself a considerable modelling challenge [32].
Simplified models of the FHEV components can be produced in a variety of universal simulation packages, such as Simulink, OpenModellica or Dymola. However, it is often much more time efficient to produce detailed component models using applicationspecific software [23]. For example, 1D CFD models of fluid circuits can be efficiently constructed in Ricardo Wave or GT-Suite, 3D FEM thermal models can be most efficiently created in Comsol or PowerTHERM, and control systems can be written using $\mathrm{C}++$ or MATLAB/Simulink code. Co-simulation, using open interfaces such as the Functional Mock-up Interface (FMI), has made it possible for these packages to communicate with each other [33]. This enables subject matter experts to work in their preferred software on a single component whilst colleagues working in other domains do the same [34-36].

Model based design enables engineers to produce a virtual representation of a system in order to reduce the requirement for physical testing [37]. However, it is important that the model is accurate enough to make informed decisions, while at the same can be developed and simulated in a reasonable timescale [31]. Cosimulation is beneficial in this regard because it increases the possibility to re-purpose existing system-level models for insertion into vehicle-level models and in-turn results from the vehicle-level models are of high enough fidelity to make component design decisions. However, care should be taken in order to maintain computational efficiency.

This paper describes the development of a high-fidelity holistic vehicle model designed for analysis of thermal energy management of a FHEV. The paper begins by providing an overview of each of the individual system models, which is followed by a description of the techniques used to efficiently integrate them with regard to both ease-of-use and computational efficiency. This is followed by the simulation methodology used to produce a set of demonstrative results and the results themselves. The paper concludes with the analysis of these preliminary results from the model and a description of planned further work.

\section{Holistic Vehicle Model}

A high-level overview of the model is shown in Figure 1. The holistic vehicle model is made up from a number of complex high-fidelity models which have been integrated into a single simulation environment through the use of advanced simulation techniques, such as co-simulation and surrogate modelling. Each of the system-level models have been developed over a number of years at Jaguar Land Rover and are actively used for system-level and component-level

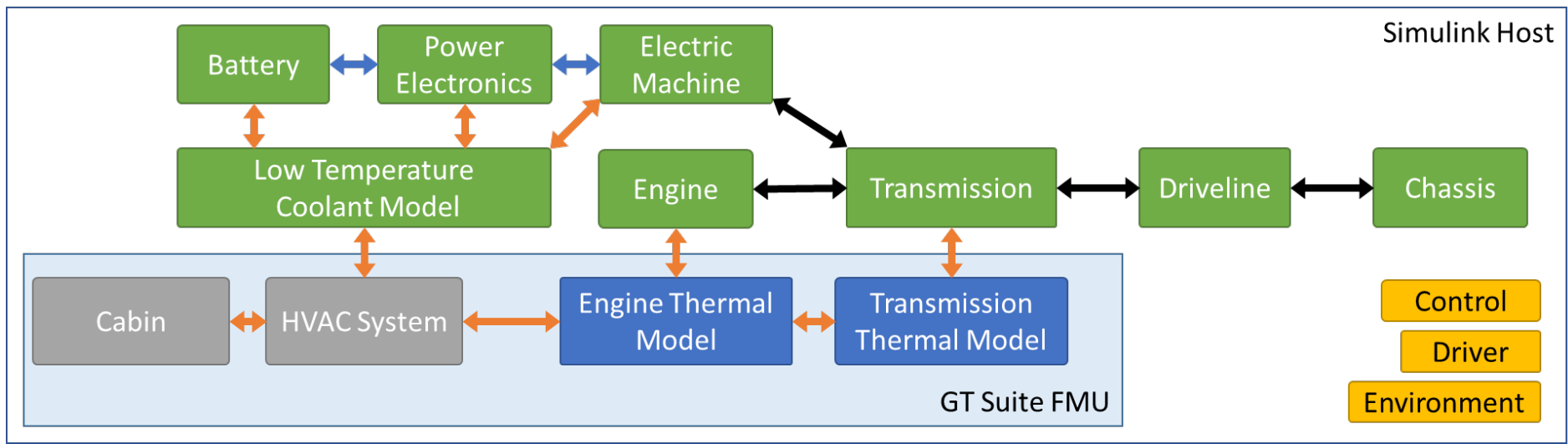

Figure 1 - Holistic model overview, arrows represent most significant thermal (orange), electrical (blue) and mechanical (black) energy flow paths

Page 2 of 15 
design. As such, they have been developed by subject matter experts and validated independently against real-world test data. The models have subsequently been adapted by Loughborough University to communicate and run efficiently with each other while maintaining the accuracy and fidelity of their results. The output is a single model which captures the flow of thermal, mechanical and electrical energy between the various systems with a high level of detail and enables analysis of the complex interactions taking place between the systems.

The vehicle simulation tool used for this project is CalSim, an internal Jaguar Land Rover tool developed in MATLAB/Simulink [38-40]. Within the CalSim vehicle model is a thermal model FMU which has been exported from GT- Suite. The GT-Suite model is based on a thermo-fluid model consisting of engine and transmission thermal models and has been adapted to include a cabin model and dual zone HVAC system model. The powertrain simulation model (CalSim) calculates powertrain heat losses and control actions which are provided to the thermal model (GT). The thermal model subsequently calculates the temperature of each of the fluids and outputs its energy requirements (due to pumps, fans, etc.) and the fluid temperatures back to the powertrain model. The fluid temperatures are then used to calculate combustion efficiency and driveline efficiency based on maps contained within the powertrain model. The high-level outputs of the model are fuel consumption, and exhaust emission output.

The ultimate purpose of the model is to assess the effect of various design changes on the overall fuel consumption and emission output of a new FHEV design and to provide a virtual system for the development of an integrated thermal energy management strategy which will be responsible for holistically managing thermal, electrical and mechanical energy in order to maximize efficiency.

\section{Powertrain Evaluation Environment}

The holistic model is hosted in a high-level vehicle simulation environment called CalSim, which is based in MATLAB/Simulink. Jaguar Land Rover currently uses CalSim to perform vehicle performance, fuel consumption and energy assessment. CalSim is a comprehensive software package which has been developed in-house at Jaguar Land Rover for over a decade. It consists of a collection of powertrain models for a range of conventional and electrified vehicle designs, packaged together with a database of legislative and inhouse test cases and a parameterization dataset for all current vehicles. It is computationally efficient and under continuous internal development in collaboration with numerous teams within Jaguar Land Rover. This makes it suitable for a wide range of tasks throughout the company including engine calibration development, hardware-in-the-loop (HiL) testing and hybrid controls development.

CalSim has a number of strengths. Firstly, the tool simulates the high-level behavior of the complete powertrain using parameter datasets which are continuously correlated to the latest available test data. This means that components which influence the thermal management, but are not a direct area of study, such as vehicle aerodynamics models, are maintained externally to the current project. In addition, it is already widely used throughout the company for fuel consumption and performance assessment meaning that results are directly comparable to that of other groups. This is of particular importance for dynamic drive-cycle simulations such as the WLTP where the influence of the driver model can have significant effect on the results. Because CalSim is already used for powertrain HiL testing, this virtually eliminates a potential cause of error between simulation and testing. Finally, CalSim contains a database of pre-programmed test cases for legislative and in-house performance and economy tests including the necessary preconditioning simulations and environment conditions. This means that the resultant holistic model can be tested over a variety of worldwide legislative and company standardized test cycles with no additional effort.

CalSim is used to simulate the vehicle powertrain, including engine, transmission, driveline and chassis. It also includes models of the electric machine (EM), power electronics and battery, However, being a high-level vehicle model, the components of CalSim are relatively low-fidelity phenomenological and empirical models. It does not capture, in sufficient detail, the complex thermal pathways required for the development of an integrated thermal energy management strategy (ITEMS). It is therefore necessary to introduce new sub-models and substitute certain components within CalSim with higher fidelity alternatives as described below.

\section{Thermo-Fluids Models}

The thermo-fluids model captures system-level thermal behavior within the powertrain during transient temperature cycles such as that of the WLTP legislative cycle. The model, built using the GT-Suite library, enables 1D CFD engine coolant and oil temperature to be calculated over transient warm-up drive cycles, and hence the mechanical losses can be calculated at each point in time. A schematic of the 1D CFD warm-up model can be found in Figure 2.

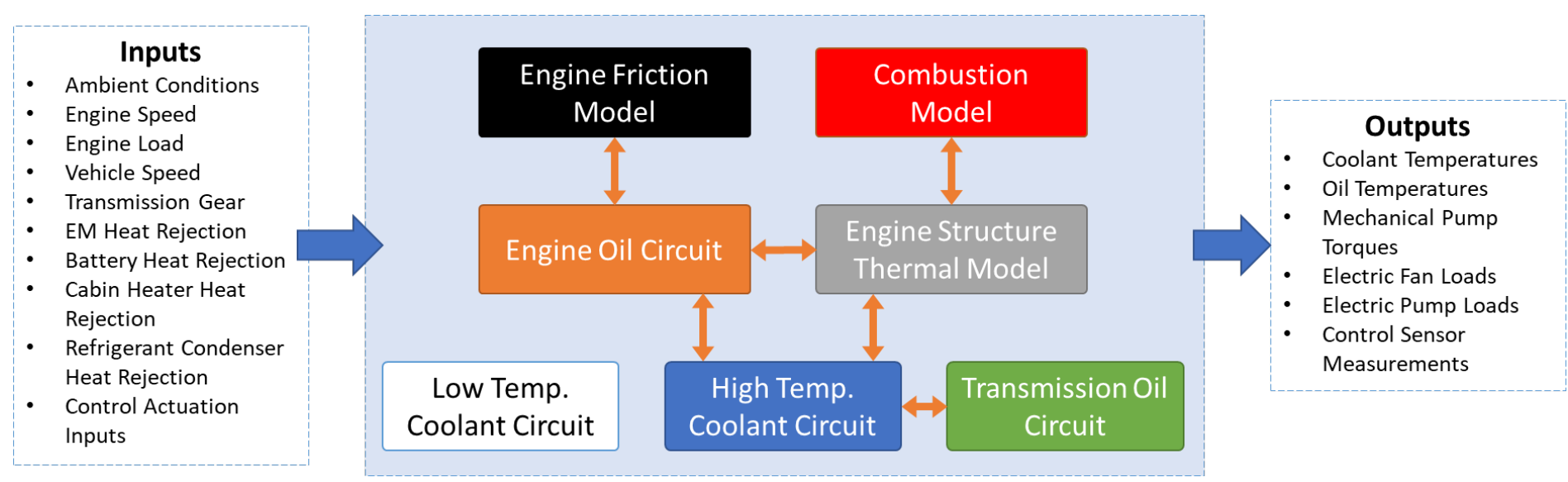

Figure 2 - Warm-up model thermal pathways 
In Figure 2, the sub-models included can be seen and the major thermal paths are captured. The sub-models include; high and low temperature coolant circuits, the engine lubrication circuit, transmission oil circuit and a model of the engine structure.

For the engine, heat is generated via a combustion and friction models based on the engine speed and load calculated by CalSim. The combustion heat enters the system through the combustion chamber (modelled via a 3D finite-element model (FEM)) and is distributed out through the liner and piston into the engine structure which is again modelled using 3D FEM including; engine head, block, pistons, valves and sump. The mechanical friction is captured through friction data generated via engine testing and numerical models enable modelling of temperature effects on each engine friction group. The level of friction subsequently impacts the combustion characteristics through varying load demand, in turn impacting heat generation, warm-up behavior and fuel consumption.

Heat resulting from the combustion and friction models is transferred to the fluids through surface connections and heat transfer coefficients generated via 3D CFD techniques. The fluid circuits are modelled with a high degree of fidelity using 1D CFD, inclusive of pressure loss maps/models for each component and all connecting hoses in order to accurately calculate the flow rates, pressures and pumping loads throughout each of the circuits. The model then outputs the temperatures of the fluids at various locations back to CalSim where is it used along with the engine speed and load to calculate the fuel consumption and engine-out emissions. In addition, mechanical (torque) and electric (current) loads are provided as outputs from the model for each fan and pump present.

Heat from combustion and engine friction is rejected into the high temperature coolant and engine oil circuits. The high temperature coolant circuit also interacts with the HVAC model through the front and rear cabin heater matrices. The heat rejected by the electric machine and battery are calculated in CalSim and used as inputs to the low temperature coolant circuit. Similarly, the transmission heat losses are used as inputs to the transmission oil circuit.

During normal operation, heat is rejected from the engine oil and transmission oil circuits into the high temperature coolant by the use of liquid-liquid engine oil (EOC) and transmission oil coolers (TOC). During warm up, the flow of heat through these components is reversed in order to promote faster oil warm-up so as to reduce friction losses. The coolant flow through the TOC can be controlled through the use of a multi-port valve in order to be able to control the heat transfer to/from the transmission. There are no dedicated oil radiators in the model.

In contrast to the transmission oil and engine oil circuits, the low temperature coolant circuit and refrigerant circuits have independent radiators and are not thermally linked to the high temperature coolant circuit, however there may be some thermal interaction due to the radiator arrangement. Air flow through the radiators is calculated using 1D CFD models based on empirical data using the vehicle speed and cooling fan flow rates as inputs.

${ }^{1}$ It should be noted that for optimal performance under a wide range of climatic conditions, the battery could be actively cooled using the refridgerant circuit in hot environments and electrical heating in cold environments. Active thermal control of the battery pack is this way enables the battery to operate more effectively under extreme Page 4 of 15
The model described in this paper is based on an existing vehicle which has been experimentally tested over a wide range of environmental conditions at the whole-vehicle level. The current control strategy passively controls the battery temperature in extreme conditions by de-rating the traction battery resulting in potentially reduced electric performance ${ }^{1}$ under these conditions. The validation of the thermal-fluids system model was performed by comparison to a number of temperature, pressure and flow rate measurements located throughout the system, taken over a series of in-house and legislative drive-cycles. A sample of the validation comparison for the WLTP is shown in Figure 3. It can be seen that the model shows an excellent correlation to the test for the high temperature coolant and oil circuits. The transmission oil temperature is also within acceptable range, although there is scope for some further work.
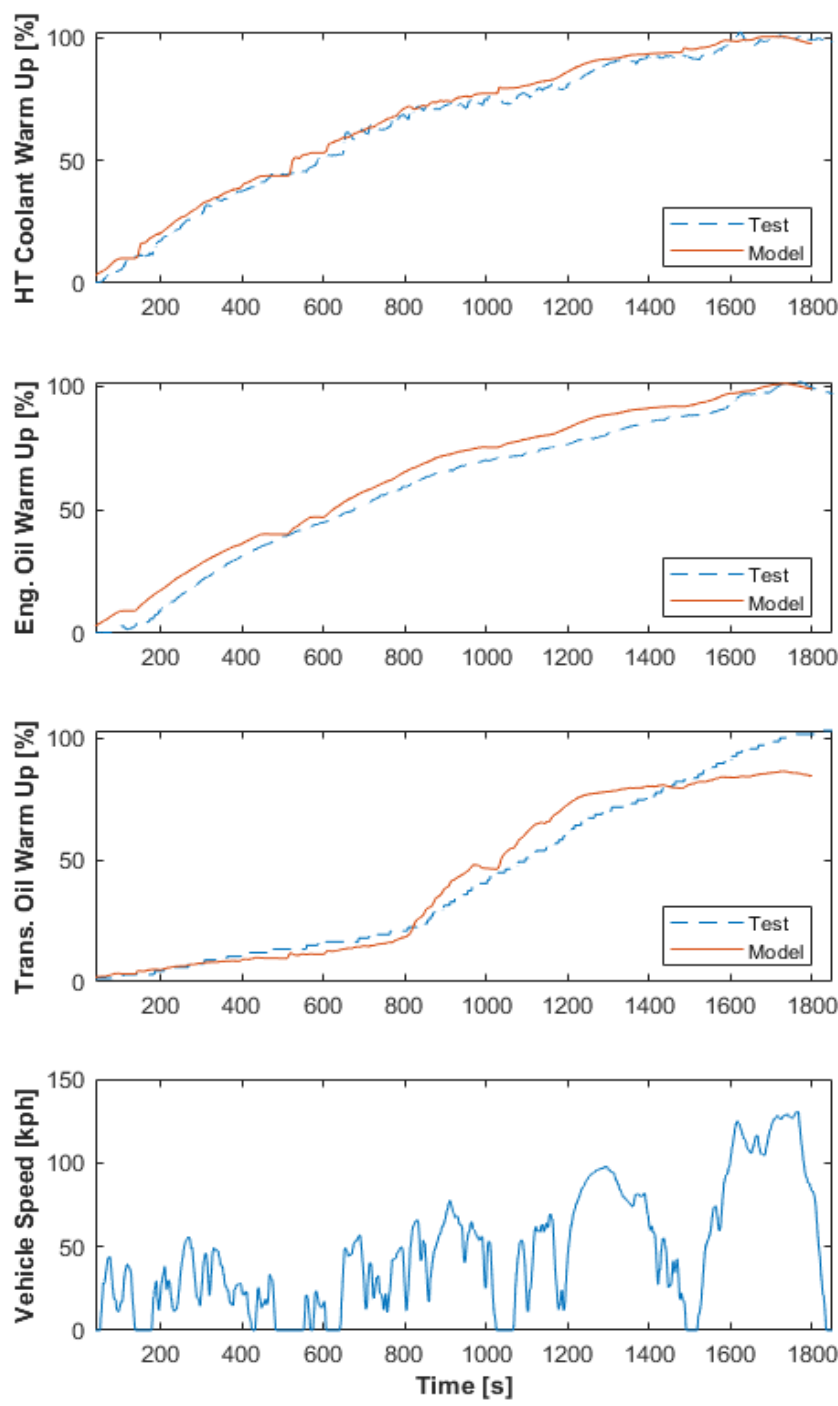

Figure 3 - Thermo-Fluids Model Validation. Warm up temperatures have been normalized as a between ambient $(0 \%)$ and normal operating temperature $(100 \%)$

conditions but consumes electrical power in order to do so. It also introduces additional complexity and cost to the vehicle design. One of the ways in which this model will be used will be to perform a cost-benefit exercise in order to examine this subject in detail. 


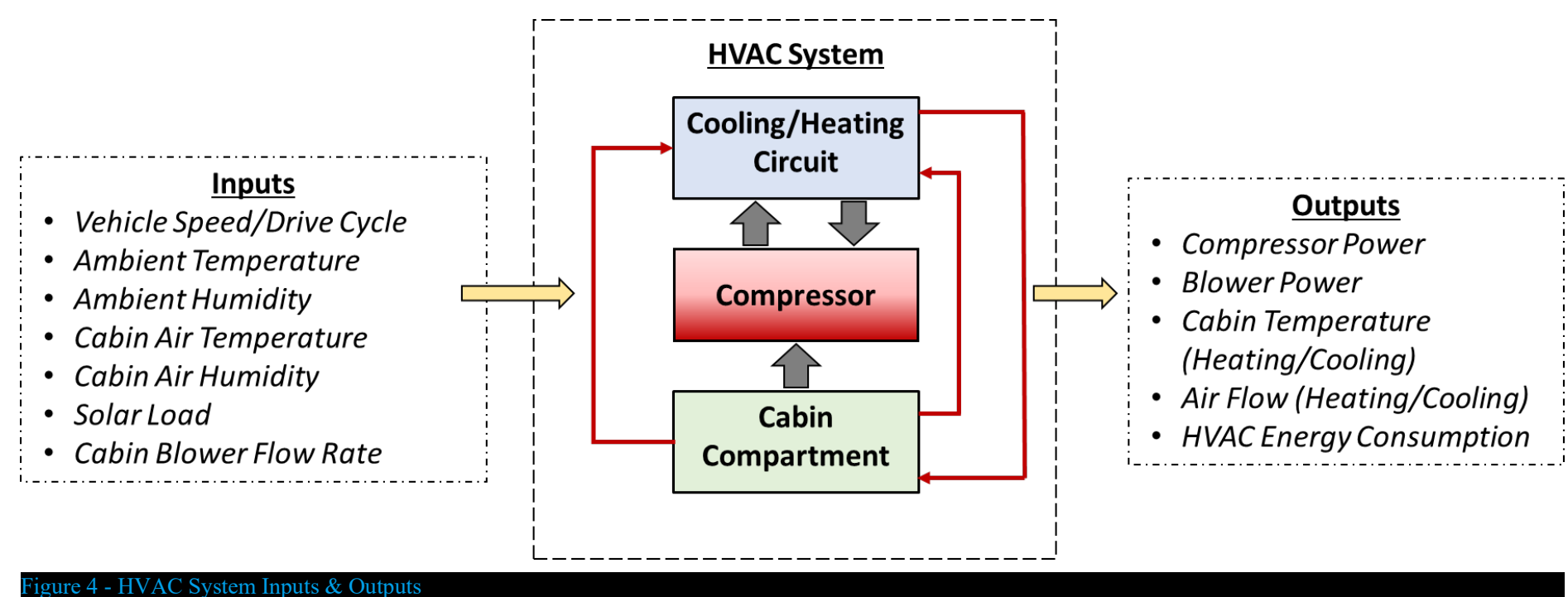

\section{HVAC \& Cabin Models}

The purpose of an automotive heating, ventilation and air conditioning (HVAC) model is to simulate the interconnected performance of all system components under various conditions to provide the thermal comfort of the passengers. A dual-zone HVAC system has been developed in GT Suite for the purpose of studying the operation of the system and its interaction with the powertrain via co-simulation. The dual HVAC system consists of a dual-zone (front and rear) cabin model, a refrigerant circuit and an air-duct system. A list of the system's inputs and outputs is given in Figure 4.

The cabin compartment was modelled as two (front and rear) lumped mass $0 \mathrm{D}$ system elements with a $1 \mathrm{D}$ air path connecting them and models the temperature response of each zone as a function of time, ambient conditions and vehicle drive cycle. The overall cabin size and structure is modelled after a medium-sized SUV. The cabin thermal balance considers the heat loads on the cabin through its surfaces by convection, radiation and conduction. The cabin element provides the load for the dual HVAC model. The two-zone cabin element includes a multitude of physical, geometrical, thermal and optical specs for its structural components - roof, floor, doors, windshield, interior etc.

The air-duct model supplies air to the cabin vents using a 1D air path model consisting of dual electric blowers (front/rear), dual electric PTC heaters, the air side of two powertrain-cabin heater matrices, and the air side of two refrigerant evaporators. Cabin air can be heated electrically or from waste engine heat and cooled using the refrigerant circuit. The temperature of the cabin vents is controlled by mixing air flow from the evaporator and heaters using flaps in the ducts. The source of the air flow to the air duct system can also be varied between $0-100 \%$ recirculation using outlets in the cabin model.

The dual refrigeration circuit consist of the refrigerant-side of two evaporators, one for each cabin compartment zones. The overall layout and structure of the model is shown in Figure 5. The refrigerant compressor and thermal expansion valves system components are empirical, while all heat exchangers are semiempirical. The baseline HVAC model uses a crank-driven mechanical compressor which receives an input in the form of engine speed and outputs torque losses to the host powertrain model. Alternatively, an electric compressor can be specified which outputs an electrical load to the host powertrain model. The refrigerant mass Page 5 of 15 flow rate, torque, power, enthalpy change and many more are calculated through the compressor performance data over a broad range of loads and speeds.

The thermal expansion valve (TXV) is built as a simple performancebased system component. The model senses the change of enthalpy and changes the valve opening. The valve changes its opening as a function of the refrigerant enthalpy at the evaporator's outlet. The TXV opening is calculated for each time step by the following dependency (1):

$$
\frac{d A}{d t}=A_{\text {nom }} \cdot \frac{\left(h_{\text {actual }}-h_{\text {target }}\right)}{\tau \cdot h_{\text {nom }}}
$$

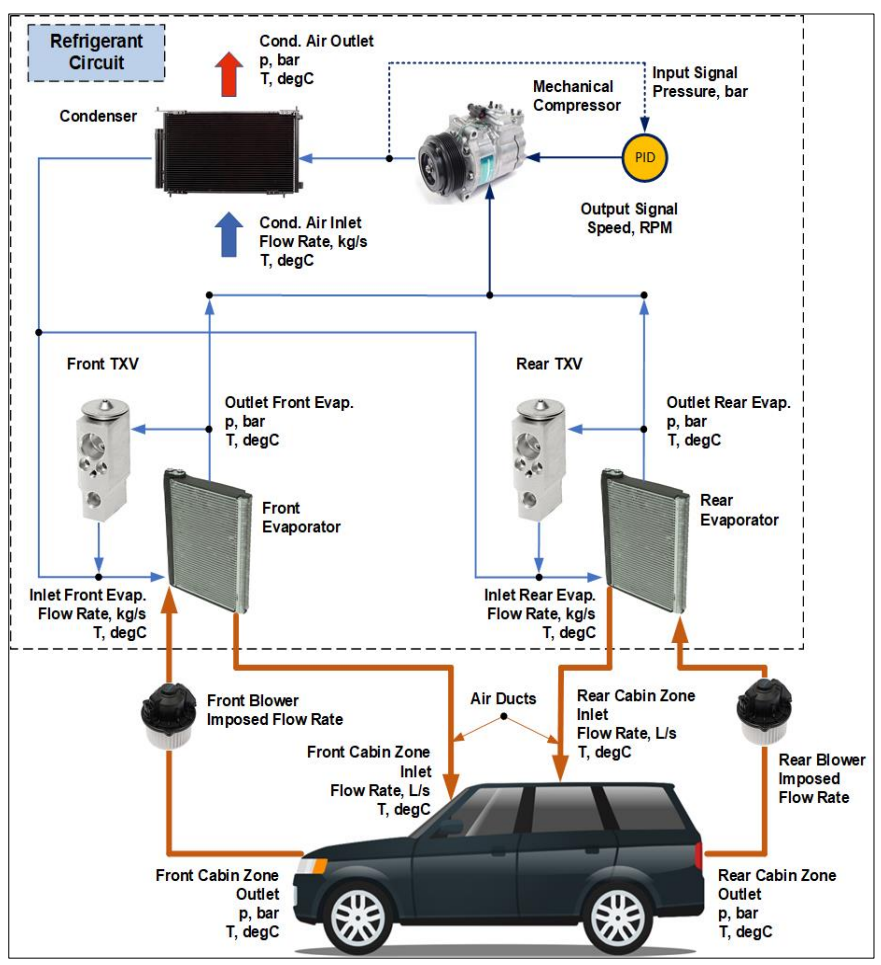

Figure 5 - Dual HVAC Model, Top Level Layout. No 
where $d A / d t$ corresponds to the orifice diameter change as a function of time, $A_{\text {nom }}$ is the maximum orifice area, $h_{\text {actual }}$ is the sensed enthalpy, $h_{\text {target }}$ is the target enthalpy, $\tau$ is the valve time constant and $h_{n o m}$ is the nominal evaporator outlet enthalpy.

All modelled components were calibrated with their real-life counterpart specification and correlated to test data; a sample validation data comparison is shown in Figure 6.

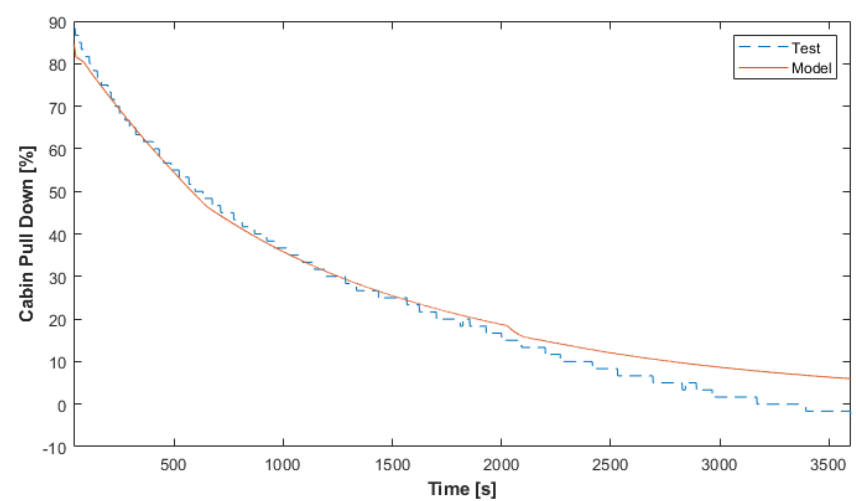

Figure 6 - A/C Pull Down Validation, normalized between ambient temperature and target temperature

An A/C pull-down test case was simulated with the baseline dual HVAC model. The ambient and initial condition of the simulation are ambient temperature of $43{ }^{\circ} \mathrm{C}$, solar load of $1000 \mathrm{~W} / \mathrm{m} 2$, ambient humidity of 0.4 , overall test/drive cycle duration of $90 \mathrm{~min}$. Figure 7 shows the normalized temperature response of each cabin compartment zone as a function the vehicles drive cycle alongside the normalized refrigeration compressor power output.
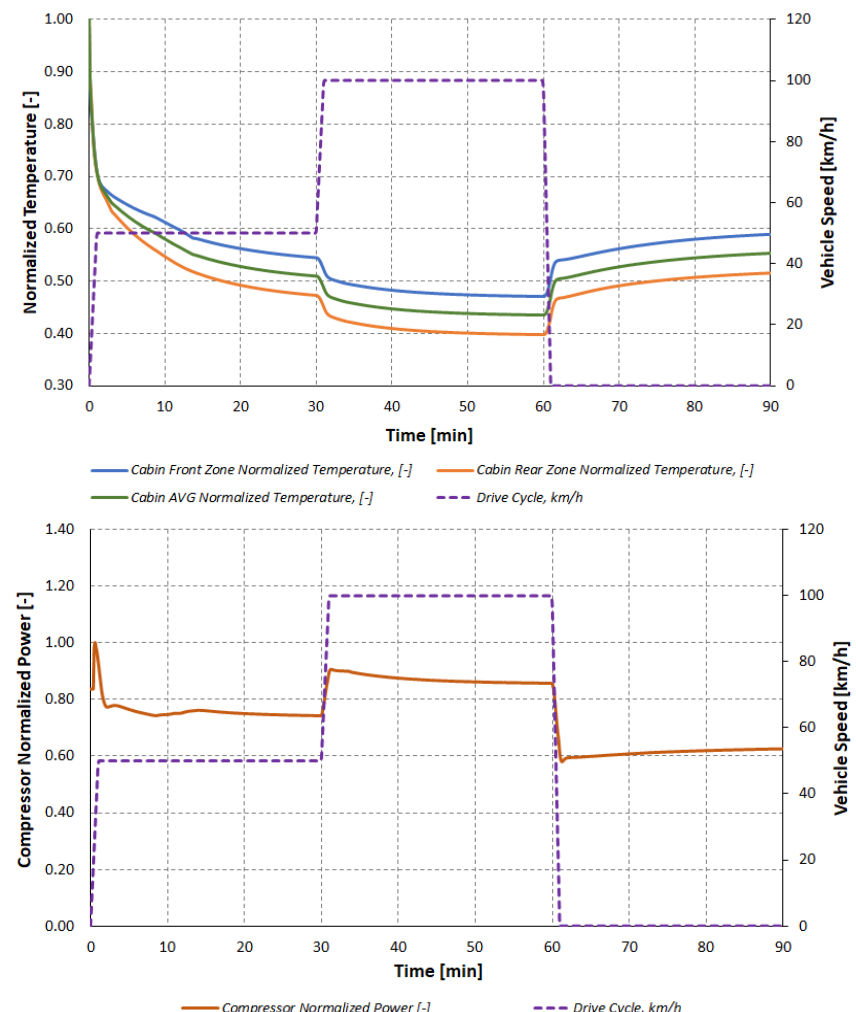

Figure 7 -Normalized Cabin Temperature Response (top) and Normalized Compressor Output Power (bottom)

\section{Underhood Model}

The purpose of the underhood model is to assess the impact of thermal encapsulation of the engine during soak periods, such as when the vehicle is parked. Encapsulation can have a significant effect on the post-soak performance of the engine due to the retention of heat within the engine and transmission structures and thermal fluids. This benefit is represented by the Ambient Temperature Correction Test (ATCT) in the WLTP.

The understanding of the flow development during early soak stage is vital to accurately predict the heat transfer coefficients for the heat retention modelling. A flow-thermal coupled CAE heat retention modelling method was developed [41] to predict the key fluids and engine components temperatures' cool-down behavior with relatively cost-effective computing demand. The method development is detailed in previous work [42], and here only a brief description is included.

To resolve the buoyancy-driven convection flow around the engine bay during the early soak period, a transient full-scale 3D CFD method utilizing a particle-based Lattice-Boltzmann Method (LBM) $[41,42]$ is used. The LBM approach is an inherently transient flow solver, which models fluid at a fundamental kinetic level using discrete Boltzmann equations governing the dynamics of particle distribution functions [23]. It tracks the motions of macromolecules through space and time to simulate flows of gases and liquids. The macroscopic hydrodynamic quantities are direct results of the moments of particle density distributions given by (2):

$\rho=\sum_{i} f_{i}(\vec{x}, t), \rho \vec{u}=\sum_{i} \vec{u}_{i} f_{i}(\vec{x}, t), \rho \varepsilon=\sum_{i} \frac{1}{2}\left(\vec{\xi}_{i}-\vec{u}\right)^{2} f_{i}(\vec{x}, t)$,

where $\rho$ is the mass density, $\vec{u}$ and $\varepsilon$ are the velocity and the internal energy density. $f(\vec{x}, t)$ describes the single particle number density $f$ at time $t$ and position $\vec{x}$. Turbulence in the anisotropic turbulent scales (or very large eddies) is directly resolved in the LBM, whiles turbulence in the dissipative and inertial ranges is modelled [23].

Figure 8 shows an example of the aerodynamic flow field simulated by the CFD of the under-hood region. It evidences a buoyancy-driven flow feature in the under-hood region where heat irradiated by the heat sources (such as the engine block, the turbo-compressor and the exhaust components) is absorbed by the surrounding internal air, increasing the fluids temperature and inducing the development of vortices and air movements around the engine bay.

Figure 9 shows an example image of a coupled simulation of the vehicle under-hood towards the end of the first WLTP cycle, which is also the beginning of the soak process. The fluid nodes represented by the dot-matrix in the image contain the aerodynamic properties and the HTCs information of the internal air computed by the transient 3D CFD. This is then seeded into the vehicle thermal model to calculate the heat transfer rates of the solids parts and the internal cooling liquids (not visualized in the image). The transient solids' surfaces temperatures predicted by the thermal model is subsequently mapped onto the CFD model as the new boundary conditions to initiate the next cycle of the transient flow simulations. The two models running simultaneously and interacts with the new data as boundary conditions of each other. The above coupled process iterates for several cycles of customized time periods. 

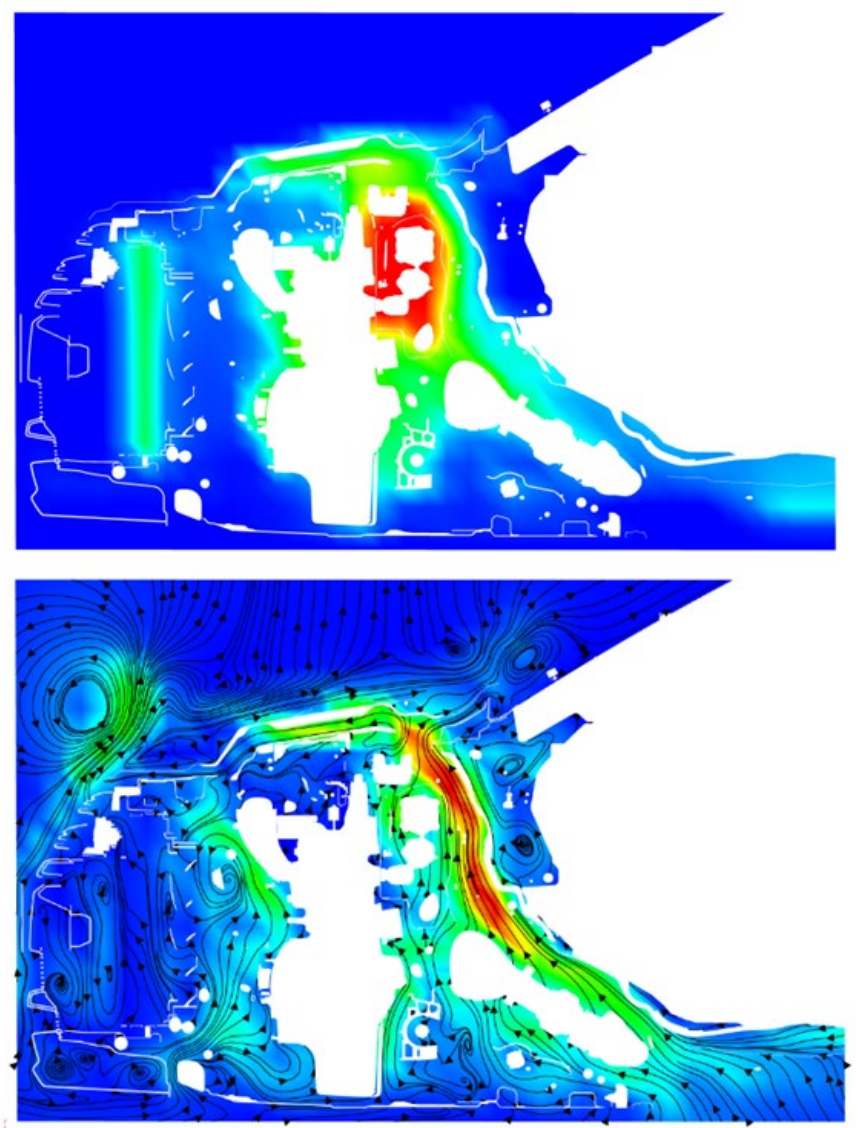

Figure 8 - Example of the buoyancy flow within the under-hood region from a full-scale 3D CFD simulation using LBM method. Top row - normalized flow temperature. Bottom row - streamlines superimposed on velocity magnitudes (color map range: $0-0.3 \mathrm{~m} / \mathrm{s}$ ).
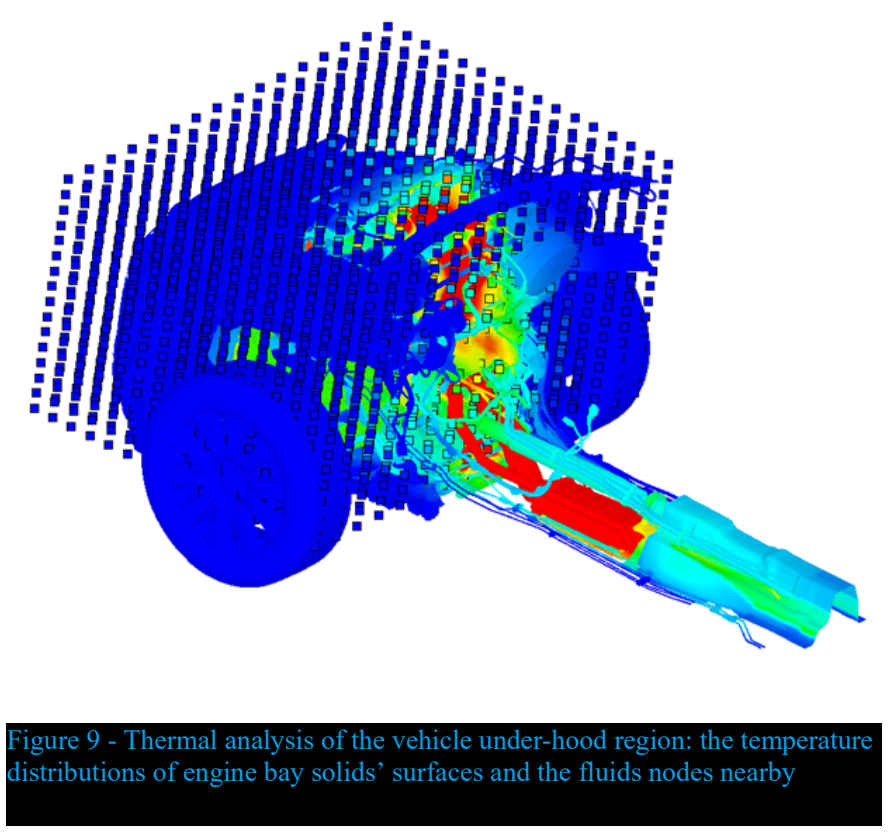

Page 7 of 15
A 9-hour vehicle cool-down was simulated using the standalone vehicle thermal model [23] and the key fluids (coolant, engine oil and transmission oil) and metal temperatures were found correlated well in between the simulation results and the vehicle testing data, see Figure 10. Differences of the coolant block, head, engine oil and transmission oil final temperature at the end of the 9-hour soak compared to the test data was $0.4,1.0,0.1$ and $0.2^{\circ} \mathrm{C}$ respectively.

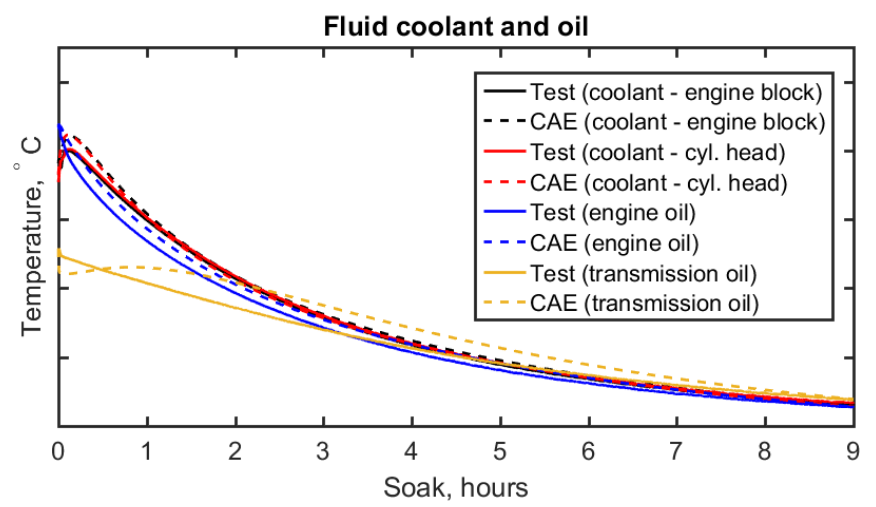

Figure 10 - Comparison of the fluids cool-down curves between CAE and test data for the coolant and oil [23]

\section{Model Integration}

In order to accurately evaluate the effect that thermal energy has on vehicle fuel consumption and $\mathrm{CO}_{2}$ emissions, the models of the powertrain mechanical and electrical systems, thermal fluids, HVAC and cabin must be simulated co-operatively. This is because they are inherently interdependent. For the reasons specified previously, the vehicle powertrain, chassis, control systems, driver and ambient environment are modelled in Simulink. The thermal fluids, HVAC and cabin are modelled using GT Suite. The models built in the two environments must be integrated into one holistic vehicle model. This is achieved using co-simulation. Unlike the other models, the underhood model runs sequentially to the holistic vehicle model. Final temperatures of components from the co-simulation model can be provided to the underhood model for initialization of the soak period, and then final temperatures from the soak can be fed back into the vehicle model for simulation of the subsequent "warm start" dynamic drive-cycle simulation. The overall simulation process is shown in Figure 11.

The GT-Suite cooling circuit model makes use of a dedicated solver automatically selected by the platform. The Simulink powertrain and vehicle body model makes use of a fixed step solver. For the integrated simulation to be stable and generate accurate results, it is imperative that each component model makes use of the numerical solver selected in its original environment. This is always true for all forms of GT model integration, however since CalSim provides test case and parameter database integration, it has been selected as the host. The authors carried out extensive tests and comparisons on the model export options available in GT-Suite. The FMU version 2.0 CS "standalone" contains not only the model but also the dedicated solver packed with the model file. Therefore, the local simulation of the model takes place on the host platform and not on the original platform using the embedded original solver. Such arrangement makes this method faster than other co-simulation solutions involving platform coupling which introduce communication latency delays into the co-simulation. Another advantage with this method is that the 


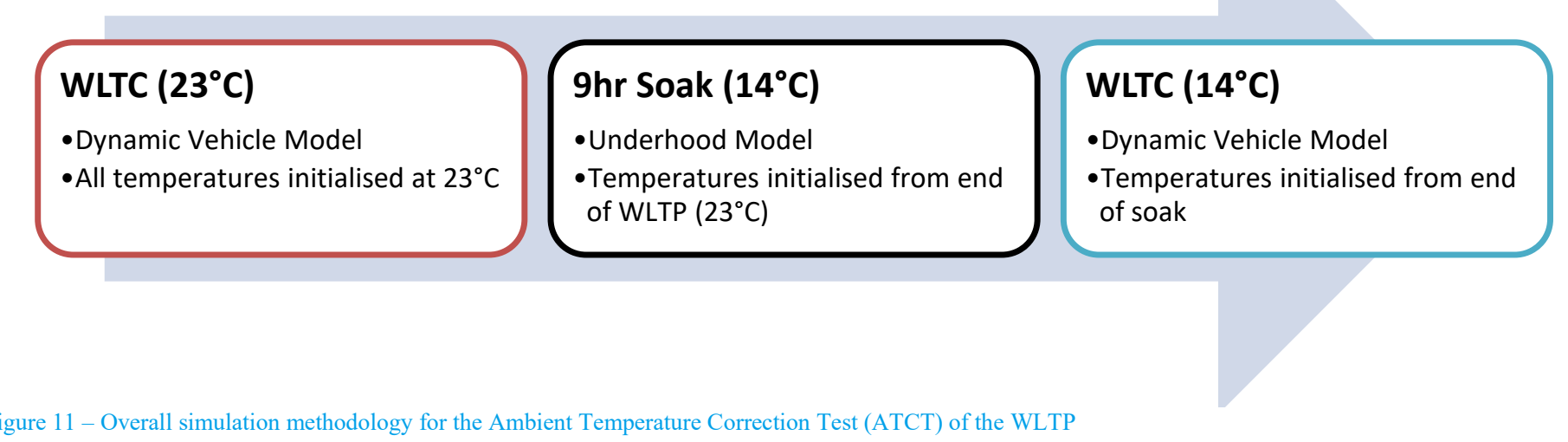

GT software does not need to be installed on the host PC meaning that the model can be shared much more readily between colleagues. However, there are a couple of downsides to this method; a much larger file size (approx. $95 \mathrm{Mb}$ vs $21 \mathrm{Mb}$ ), and the inability to view real-time plots of the GT model variables during simulation (however, if necessary, signals can be defined as outputs to the FMU and plotted in real-time using Simulink scopes).

As shown in Figure 12, the GT-Suite thermal model was exported to FMI version 2.0 CS Standalone packaged with its dedicated GT numerical solver and then imported to the global Simulink vehicle model with the use of the dedicated Simulink FMU Import block. The vehicle powertrain and body models are parts of the global Simulink numerical integration, and as a result, they follow the time step of the Simulink model. The cooling system model runs on a separate local simulation based on the dedicated GT solver embedded to the FMU model. The global Simulink model controls the execution of the local cooling circuit simulation and the communication between the global and the local simulation. The communication time step between the global and the local simulation matches the time step of the global Simulink model.

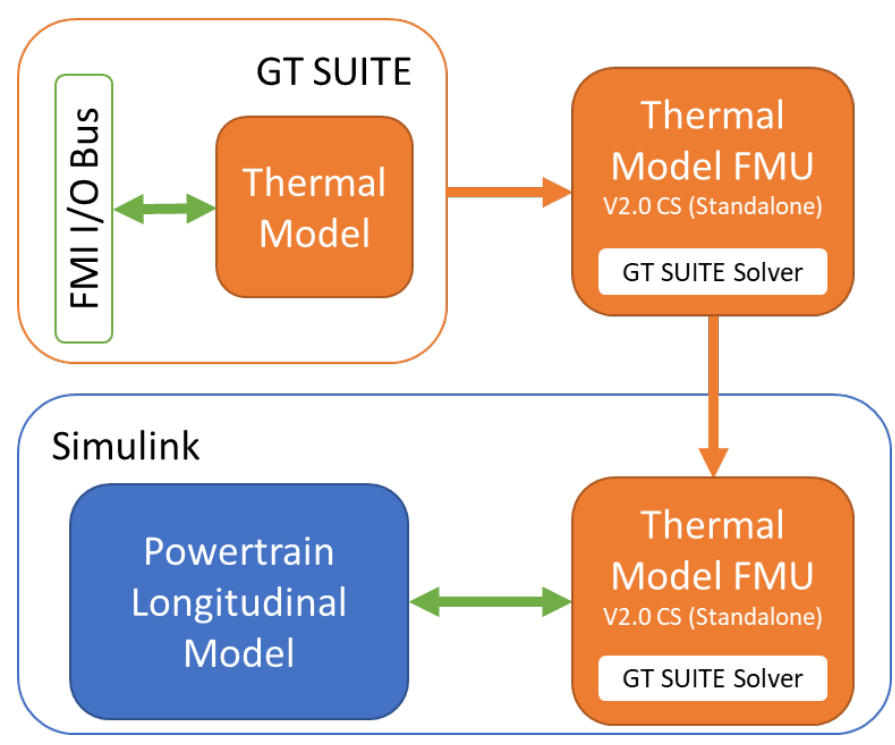

Figure 12 - Interfaces and communications between the global and the local simulations via FMU CS standalone

\section{Results}

In order to demonstrate the model, a sports utility vehicle has been simulated over the WLTC using a variety of initial temperatures ranging between $-7^{\circ} \mathrm{C}$ and $50^{\circ} \mathrm{C}$ in order to assess the fuel consumption and $\mathrm{CO}_{2}$ emissions. In addition, results from a 9-hour soak experiment have been used to initialize WLTC simulations at $14^{\circ} \mathrm{C}$ in order to assess the potential benefits of thermal encapsulation on the engine.

The results of a standard WLTC drive cycle in a $23^{\circ} \mathrm{C}$ ambient temperature are shown in Figure 15 (Appendix). All internal temperatures have also been initialized at $23^{\circ} \mathrm{C}$ to simulate a long soak period in a controlled environment where the complete vehicle has reached ambient temperature. It can be seen that the engine takes approximately 14 mins to reach operating temperature. The represents almost the first half of the test. During this time, the transmission temperature gradually rises, however once the engine reaches operating temperature, the transmission oil/coolant heat exchanger begins to operate in "warm-up" mode directing waste heat from the coolant to the transmission oil. The transmission oil begins to warm up at a faster rate and reaches operating temperature around 4 minutes later. It should also be noted that this level of detail was not present in the vehicle model before development of the cosimulation model.

Figure 13 shows the effect of ambient conditions on the fuel consumption and $\mathrm{CO} 2$ emissions when compared to the standard test temperature of $23^{\circ} \mathrm{C}$. For all of these simulations, it is assumed that the initial temperatures of the fluids, cabin, and vehicle structure have all reached the ambient temperature. Both air conditioning and electric heating of the cabin are disabled. As would be expected, increased temperature up to $50^{\circ} \mathrm{C}$ results in a small fuel saving of around $1 \%$ due to the reduced warm-up time. For the same reason, reduced temperatures of $14^{\circ} \mathrm{C}$ and $-7^{\circ} \mathrm{C}$ result in increased fuel consumption of $0.5 \%$ and $2.5 \%$ respectively.

The effect of stationary soak time is shown by Figure 14. In this experiment, the temperatures of the model components were initialized based on their expected temperatures from the underhood buoyancy model (shown in the lowest plot). Again, both air conditioning and electric heating of the cabin are disabled. A dynamic WLTP test cycle was run and the fuel consumption and exhaust emissions calculated. The upper plot shows the difference in fuel consumption when compared to a standard WLTP test cycle at $23^{\circ} \mathrm{C}$. The middle plot shows the same for $\mathrm{CO}_{2}$ emissions. 

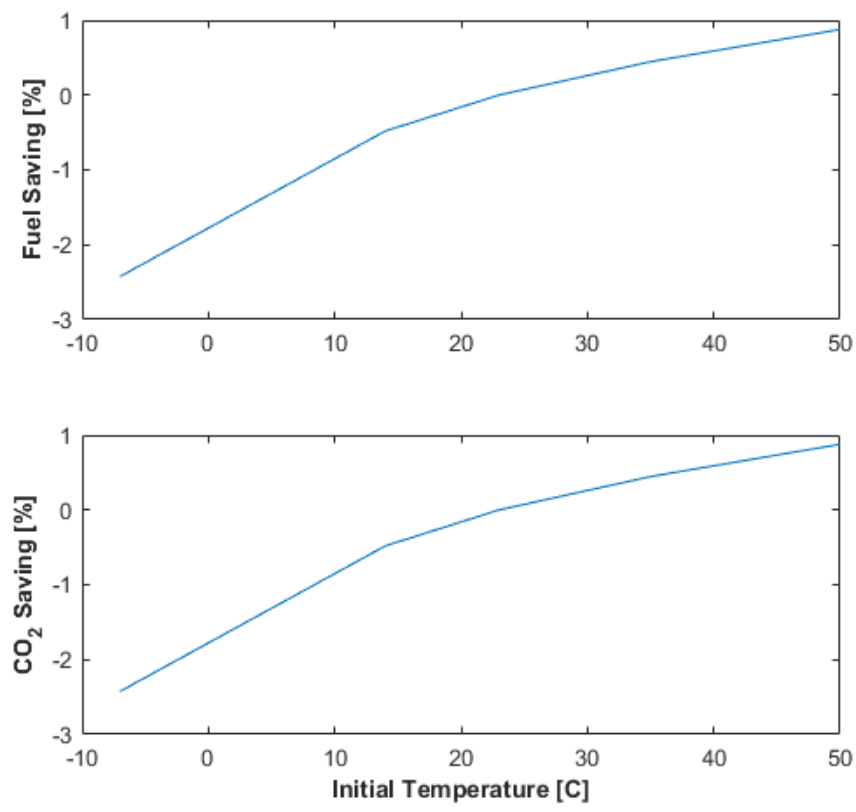

Figure 13 - WLTP Fuel (top) and $\mathrm{CO}_{2}$ (bottom) saving vs. Ambient Temperature. It is assumed that the vehicle is soaked, and all initial temperatures have reached ambient conditions

It is shown that zero soak time results in a maximum fuel saving of around $1.5 \%$. Figure 16 (appendix) allows more detailed analysis of this result. It can be seen that after the beginning of the test, the fluid temperatures do not increase significantly showing that the vehicle was approximately at full operating temperature after the first WLTP test cycle. The fuel saving takes place as a direct result of the increased initial temperature over the same period (800s) as the engine warm up in the baseline WLTP test.

As the vehicle is soaked for a longer period the fuel $/ \mathrm{CO}_{2}$ saving gradually decreases down to a minimum of $0.25 \%$ after 9 hours (corresponding to the WLTP ATCT conditions). Examination of the results shows that the fluid temperatures are between $20-30^{\circ} \mathrm{C}$ after the 9-hour soak. As a result, the initial conditions are similar to that of the baseline test and the warm-up time is approximately the same (see Figure 17, appendix). Note that it is possible to have an increased fuel consumption for the ATCT due to the lower ambient temperature of $14^{\circ} \mathrm{C}$ compared to $23^{\circ} \mathrm{C}$ (as shown in Figure 13). It should be noted that both the anticipated fuel and $\mathrm{CO}_{2}$ savings fall most rapidly in the first hour after of the soak due to the fact that this is when the fluid temperatures, especially transmission temperature, fall at a higher rate.

Finally, it should be noted that the encapsulation of the tested vehicle is minimal and that gains of approximately $10^{\circ} \mathrm{C}$ after 9 hours may be expected from concurrent work on this project [27]. According to Figure 14, this would correspond to a fuel/ $/ \mathrm{CO}_{2}$ saving of around $0.5 \%$.

Page 9 of 15
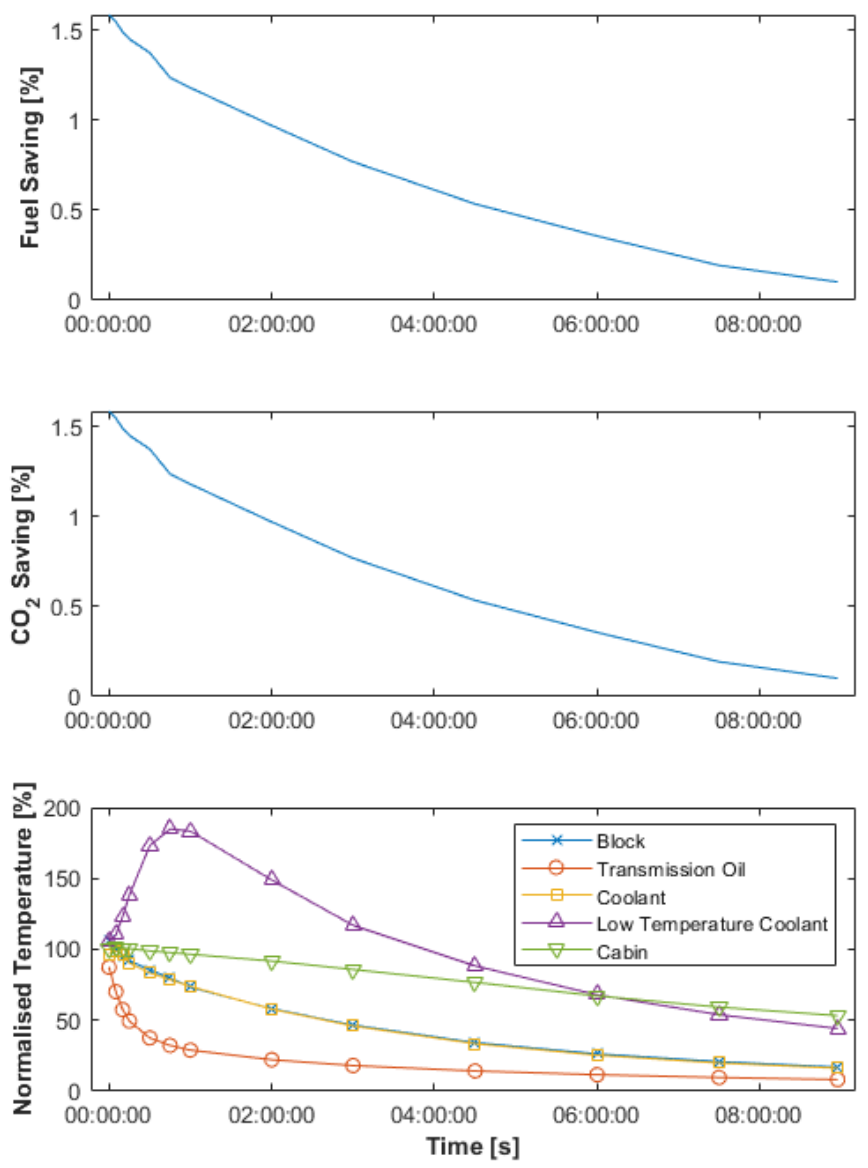

Figure 14 - Effect of soak time on fuel consumption and $\mathrm{CO}_{2}$ emissions The upper two plots show the difference in fuel consumption and $\mathrm{CO}_{2}$ emissions, respectively, when compared to standard $23^{\circ} \mathrm{C}$ WLTP test. The lower plots show the temperature of a selection of model components after this period of time. Temperatures have been normalized as a between ambient $(0 \%)$ and normal operating temperature $(100 \%)$.

\section{Conclusions}

This model has been created as a plant model for the development of an integrated thermal energy management strategy responsible for simultaneously managing the electrical, mechanical and thermal energy of a full hybrid electric vehicle. It will also be used to set design specifications for electrified components. It has been successfully shown that the model demonstrates the effect of engine and transmission warm-up on the overall vehicle efficiency with a high level of detail and enables detailed analysis of the complex interactions between thermal and electrical components.

The complete model run time can be split into three parts as shown in Figure 11. The first and final sections of the methodology involve running the main dynamic co-simulation which has a runtime of around 6.5 hours for a 30 -minute drive-cycle using a modern desktop PC (real-time factor of 13). Previous work by the authors has shown that this can be reduced to close to real time (approx. 40 minutes) by reducing the 3D FEM engine structure model into a lumped mass model with minimal loss of the overall fidelity. The second section of the methodology involves running the 3D CFD underhood model. This step is much more computationally intensive; taking around 23,652 CPU-hours ( $\sim 61.6 \mathrm{hr}$ on 384 CPUs) for a 9 hour simulation, however it does not need to be repeated for the vast majority of design changes (e.g., e-Compressor sizing, EMS control changes, etc.). 
The model is under continuous development across multiple groups in Jaguar Land Rover and at Loughborough University. One of the advantages of the modular co-simulation architecture used in this model is that each group can work on their respective module in parallel, providing updates to each other at regular intervals. To achieve this successfully, the project team has found that it is important to ensure continuous review and feedback between the separate systems groups, especially regarding the integration of the modules into the holistic architecture. Any changes to the modules during integration (including model changes, interface changes, and even solver settings) are fed back to the relevant system group for review. This minimizes the integration effort by ensuring future updates already incorporate integration changes and ensures that the integrated modules still meet validation criteria at the systems level.

Validation at the vehicle-level can also be performed by each system group within their area of expertise. Each group can use the full model for comparison to the independent system and to test data. Because the co-simulation model portrays components external to the respective system with a much higher fidelity than would be achieved using traditional simulation techniques (e.g., simplified models), this often makes it easier to trace down the cause of discrepancies with respect to vehicle test data. Overall, this serves to increase the efficiency of vehicle development, especially in areas where there are complex interactions between coupled systems.

\section{Future Work}

As mentioned, the model and results presented in this work represent the baseline vehicle for the Virbius project which uses a crank-driven $\mathrm{A} / \mathrm{C}$ compressor and passive thermal management of the traction battery. The model is also capable of using an electric compressor model and work is on-going in order to set the required specifications for this component along with a number of other electrified components. The current model uses reduced order low-temperature coolant circuit and exhaust aftertreatment models. Future work is planned in order to incorporate high-fidelity models of these components into the simulation environment. Incorporation of a highfidelity low temperature coolant model with refrigerant cooling and electric heating will enable a detailed cost-benefit analysis of active battery thermal management. Inclusion of a thermal aftertreatment model will enable more accurate calculation of other exhaust emissions species, such as NOx and HC, during warm up as well as further potential opportunities for ITEMS optimization.

\section{Contact Information}

\section{Dr Tom Fletcher}

Dept. of Aeronautical and Automotive Engineering, Loughborough University

Loughborough

LE11 3TU

T.P.Fletcher@lboro.ac.uk

\section{Acknowledgments}

The authors would like to acknowledge the funding support from the Innovate UK and the Advanced Propulsion Centre (APC) for carrying out this work. We would also like to acknowledge the support from Jaguar Land Rover Automotive PLC for providing resources and the support of Gamma Technologies for providing GTSUITE software and associated support.

\section{Definitions/Abbreviations}

A/C air conditioning

ATCT ambient temperature correction test

BEV battery electric vehicle

CAE computer aided engineering

CFD computational fluid dynamics

EMS energy management strategy

FEM finite element modelling

FHEV full hybrid electric vehicle

FMI functional mock-up interface

FMU functional mock-up unit

HC hydrocarbons

HEV hybrid electric vehicle

HiL hardware-in-the-loop

HTC heat transfer coefficient

HVAC heating ventilation and air conditioning

ICE internal combustion engine

ITEMS integrated thermal energy management strategy

LBM Lattice-Boltzmann method

LEZ low emission zone

MHEV mild hybrid electric vehicle

NOx

PM

PTC

SUV

TXV

WLTC

WLTP

ZEZ

particulate matter

positive temperature coefficient

sports utility vehicle

thermal expansion valve

world light-transport test cycle

world light-transport test protocol

zero emission zone

\section{References}

1. IEA, "CO2 Emissions from Fuel Combustion,” 2018.

2. EPA, "NOx: How nitrogen oxides affect the way we live and breathe," Washington, 1998.

3. Borup, R., Meyers, J., Pivovar, B., Kim, Y.S., Mukundan, R., Garland, N., Myers, D., Wilson, M., Garzon, F., and Wood, D., "Scientific aspects of polymer electrolyte fuel cell durability and degradation," Chemical Reviews 107(10):3904-3951, 2007, doi:10.1021/cr0501821.

4. Berckmans, G., Messagie, M., Smekens, J., Omar, N., Vanhaverbeke, L., and Mierlo, J. van, "Cost Projection of State of the Art Lithium-Ion Batteries for Electric Vehicles Up to 2030," Energies 10(9):1314, 2017, doi:10.3390/en10091314.

5. Azadfar, E., Sreeram, V., and Harries, D., "The investigation of the major factors influencing plug-in electric vehicle driving patterns and charging behaviour," Renewable and Sustainable Energy Reviews 42:1065-1076, 2015, doi:10.1016/j.rser.2014.10.058.

6. Requia, W.J., Adams, M.D., Arain, A., Koutrakis, P., and Ferguson, M., Carbon dioxide emissions of plug-in hybrid electric vehicles: A life-cycle analysis in eight Canadian cities, Renewable and Sustainable Energy Reviews, 2017, doi:10.1016/j.rser.2017.05.105.

7. Yang, Y., Ali, K.A., Roeleveld, J., and Emadi, A., "State-ofthe-art electrified powertrains - hybrid, plug-in, and electric

Page 10 of 15 
vehicles," International Journal of Powertrains 5(1):1, 2016, doi:10.1504/ijpt.2016.075181.

8. Shojaei, S., Robinson, S., McGordon, A., and Marco, J., "Passengers vs. Battery: Calculation of Cooling Requirements in a PHEV," SAE Technical Paper 2016-010241, ISBN 9780198294146, 2016, doi:10.4271/2016-010241 .

9. Zhao, D., Stobart, R., Dong, G., and Winward, E., "RealTime Energy Management for Diesel Heavy Duty Hybrid Electric Vehicles," IEEE Transactions on Control Systems Technology 23(3):829-841, 2015, doi:10.1109/TCST.2014.2343939.

10. Nüesch, T., Cerofolini, A., Mancini, G., Cavina, N., Onder, C., and Guzzella, L., "Equivalent Consumption Minimization Strategy for the Control of Real Driving NOx Emissions of a Diesel Hybrid Electric Vehicle," Energies 7(5):3148-3178, 2014, doi:10.3390/en7053148.

11. Finesso, R., Spessa, E., and Venditti, M., "Layout design and energetic analysis of a complex diesel parallel hybrid electric vehicle," Applied Energy 134:573-588, 2014, doi:10.1016/j.apenergy.2014.08.007.

12. Yang, C., Li, L., You, S., Yan, B., and Du, X., "Cloud computing-based energy optimization control framework for plug-in hybrid electric bus," Energy 125:11-26, 2017, doi:10.1016/j.energy.2017.02.102.

13. Keuth, N., Altenstrasser, H., Kunzfeld, A., and Martini, E., "Advanced Methods for Calibration and Validation of Diesel-ECU Models Using Emission and Fuel Consumption Optimization and Prediction During Dynamic Warm Up Tests (EDC)," SAE Technical Paper Series 26(0113), 2013, doi:10.4271/2013-26-0113.

14. Chalet, D., Lesage, M., Cormerais, M., and Marimbordes, T., "Nodal modelling for advanced thermal-management of internal combustion engine," Applied Energy 190:99-113, 2017, doi:10.1016/j.apenergy.2016.12.104.

15. Ibrahim, T.M., Syahir, A.Z., Zulkifli, N.W.M., Masjuki, H.H., and Osman, A., "Enhancing vehicle's engine warm up using integrated mechanical approach," IOP Conference Series: Materials Science and Engineering 210(1), 2017, doi:10.1088/1757-899X/210/1/012064.

16. Yuksel, T., Litster, S., Viswanathan, V., and Michalek, J.J., "Plug-in hybrid electric vehicle LiFePO4 battery life implications of thermal management, driving conditions, and regional climate," Journal of Power Sources 338:49-64, 2017, doi:10.1016/j.jpowsour.2016.10.104.

17. Huria, T., Ceraolo, M., Gazzarri, J., and Jackey, R., "High fidelity electrical model with thermal dependence for characterization and simulation of high power lithium battery cells," 2012 IEEE International Electric Vehicle Conference, IEVC 2012 1-8, 2012, doi:10.1109/IEVC.2012.6183271.
18. Lim, D.H., Lee, M.-Y., Lee, H.-S., and Kim, S.C., "Performance Evaluation of an In-Wheel Motor Cooling System in an Electric Vehicle/Hybrid Electric Vehicle," Energies 7(2):961-971, 2014, doi:10.3390/en7020961.

19. Moskalik, A., Hula, A., Barba, D., and Kargul, J., "Investigating the Effect of Advanced Automatic Transmissions on Fuel Consumption Using Vehicle Testing and Modeling," SAE International Journal of Engines 9(3):1916-1928, 2016.

20. Kwon, H., Sprengel, M., and Ivantysynova, M., "Thermal modeling of a hydraulic hybrid vehicle transmission based on thermodynamic analysis," Energy 116(1):650-660, 2016, doi:10.1016/j.energy.2016.10.001.

21. Liu, Y., Peng, J., Wang, B., Qin, D., and Ye, M., "Bulk temperature prediction of a two-speed automatic transmission for electric vehicles using thermal network method and experimental validation," Proceedings of the Institution of Mechanical Engineers, Part D: Journal of Automobile Engineering 233(10):2585-2598, 2018, doi:10.1177/0954407018802667.

22. Titov, E., Lustbader, J., Leighton, D., and Kiss, T., "MATLAB/Simulink Framework for Modeling Complex Coolant Flow Configurations of Advanced Automotive Thermal Management Systems," SAE Technical Paper 2016-01-0230, SAE International, 2016, doi:10.4271/201601-0230.

23. Yuan, R., Sivasankaran, S., Dutta, N., Jansen, W., and Ebrahimi, K., "Numerical investigation of buoyancy-driven heat transfer within engine bay environment during thermal soak," Applied Thermal Engineering 164:114525, 2020, doi:https://doi.org/10.1016/j.applthermaleng.2019.114525.

24. Harikrishnan, T.V., Sunder, A., and Hoard, J., "Study of Effects of Thermal Insulation Techniques on a Catalytic Converter for Reducing Cold Start Emissions," SAE Technical Papers 2018-April:1-11, 2018, doi:10.4271/201801-1431.

25. Weilenmann, M., Favez, J.Y., and Alvarez, R., "Cold-start emissions of modern passenger cars at different low ambient temperatures and their evolution over vehicle legislation categories," Atmospheric Environment, 2009, doi:10.1016/j.atmosenv.2009.02.005.

26. Minovski, B. and Lofdahl, L., "Study of Software Integration for Transient Simulation of Future Cooling System for Heavy Truck Application," SAE Technical Paper 2014-010653, 2014, doi:10.4271/2014-01-0653.

27. Yuan, R., Dutta, N., Sivasankaran, S., Jansen, W., and Ebrahimi, K., "Heat retention analysis with thermal encapsulation of powertrain under natural soak environment," International Journal of Heat and Mass Transfer 147:118940, 2020, doi:10.1016/J.IJHEATMASSTRANSFER.2019.118940.

28. Mattarelli, E. and Muscio, A., "Potential of Thermal Engine Encapsulation on Automotive Diesel Engines," SAE

Page 11 of 15 
Technical Papers 2005-Septe, 2005, doi:10.4271/2005-24067.

29.

Chen, K.H., Johnson, J., Merati, P., and Davis, C., "Numerical investigation of buoyancy-driven flow in a simplified underhood with open enclosure," $S A E$ International Journal of Passenger Cars - Mechanical Systems 6(2), 2013, doi:10.4271/2013-01-0842.

30. Sweetman, B., Schmitz, I., Hupertz, B., Shaw, N., and Goldstein, J., "Experimental and Numerical Investigation of Vehicle Drive and Thermal Soak Conditions in a Simplified Engine Bay," SAE International Journal of Passenger Cars - Mechanical Systems 10(2), 2017, doi:10.4271/2017-010147.

31. Traussnig, A., Petutschnig, H., Ennemoser, A., Stolz, M., and Tizianel, M., "Vehicle Thermal Management Simulation Method Integrated in the Development Process from Scratch to Prototype," SAE Technical Paper 2014-01-0668, SAE International, ISBN 2014010668, 2014, doi:10.4271/201401-0668.

32. Wang, Y., Gao, Q., Zhang, T., Wang, G., Jiang, Z., and Li, Y., "Advances in Integrated Vehicle Thermal Management and Numerical Simulation," Energies 10:1636, 2017 , doi:10.3390/en10101636.

33. Gomes, C., Thule, C., Broman, D., Larsen, P.G., and Vangheluwe, H., "Co-simulation : State of the art," 2017.

34. Kalantzis, N., Fletcher, T., Pezouvanis, A., Ebrahimi, K., Cary, M., and Lygoe, B., "Modelling Environment for Holistic Vehicle Simulation," in: Ebrahimi, K., ed., 4th Biennial International Conference on Powertrain Modelling and Control (PMC 2018), Loughborough: 120, 2018.

35. Fletcher, T., Kalantzis, N., Cary, M., Lygoe, B., Pezouvanis, A., and Ebrahimi, K., "Automated Model Based Engine Calibration Procedure using Co-Simulation," in: Ebrahimi, K., ed., 4th Biennial International Conference on Powertrain Modelling and Control (PMC 2018), Loughborough: 118, 2018.

36. Shojaei, S., McGordon, A., Robinson, S., Marco, J., and Jennings, P., "Developing a model for analysis of the cooling loads of a hybrid electric vehicle by using cosimulations of verified submodels," Proceedings of the Institution of Mechanical Engineers, Part D: Journal of Automobile Engineering 232(6):766-784, 2018, doi:10.1177/0954407017707099.

37. Mikelsons, L. and Samlaus, R., "Towards Virtual Validation of ECU Software using FMI," Proceedings of the 12th International Modelica Conference, Prague, Czech Republic, 2017, doi:10.3384/ecp17132307.

38. Carey, C., McAllister, M., Sandford, M., Richardson, S., Pierson, S., Darnton, N., Bredda, S., Akehurst, S., Brace, C., Turner, J., Pearson, R., Luard, N., Martinez-Botas, R., Copeland, C., Lewis, M., and Fernandes, J., "Extreme engine downsizing," Innovations in Fuel Economy and Sustainable Road Transport 135-147, 2011.
39. Turner, J.W.G., Popplewell, A., Patel, R., Johnson, T.R., Darnton, N.J., Richardson, S., Bredda, S.W., Tudor, R.J., Bithell, C.I., Jackson, R., Remmert, S.M., Cracknell, R.F., Fernandes, J.X., Lewis, A.G.J., Akehurst, S., Brace, C.J., Copeland, C., Martinez-Botas, R., Romagnoli, A., and Burluka, A.A., "Ultra Boost for Economy: Extending the Limits of Extreme Engine Downsizing," SAE International Journal of Engines 7(1):387-417, 2014, doi:10.4271/201401-1185.

40. Meghani, A., Allen, J., Turner, J.W.G., Popplewell, A., Marshall, D.J., Hoyle, J.S., McBroom, S., Urista, R., and Bazyn, M., "Effects of Charging System Variability on the Performance and Fuel Economy of a Supercharged SparkIgnition Engine," SAE Technical Papers 2015-April(April), 2015, doi:10.4271/2015-01-1286.

41. Exa Corp., "PowerFLOW User's Guide 3.0," Lexington, MA, 1998.

42. Lockard, D.P., Luo, L.S., Milder, S.D., and Singer, B.A., "Evaluation of PowerFLOW for aerodynamic applications," Journal of Statistical Physics, 2002, doi:10.1023/A:1014539411062.

Page 12 of 15 

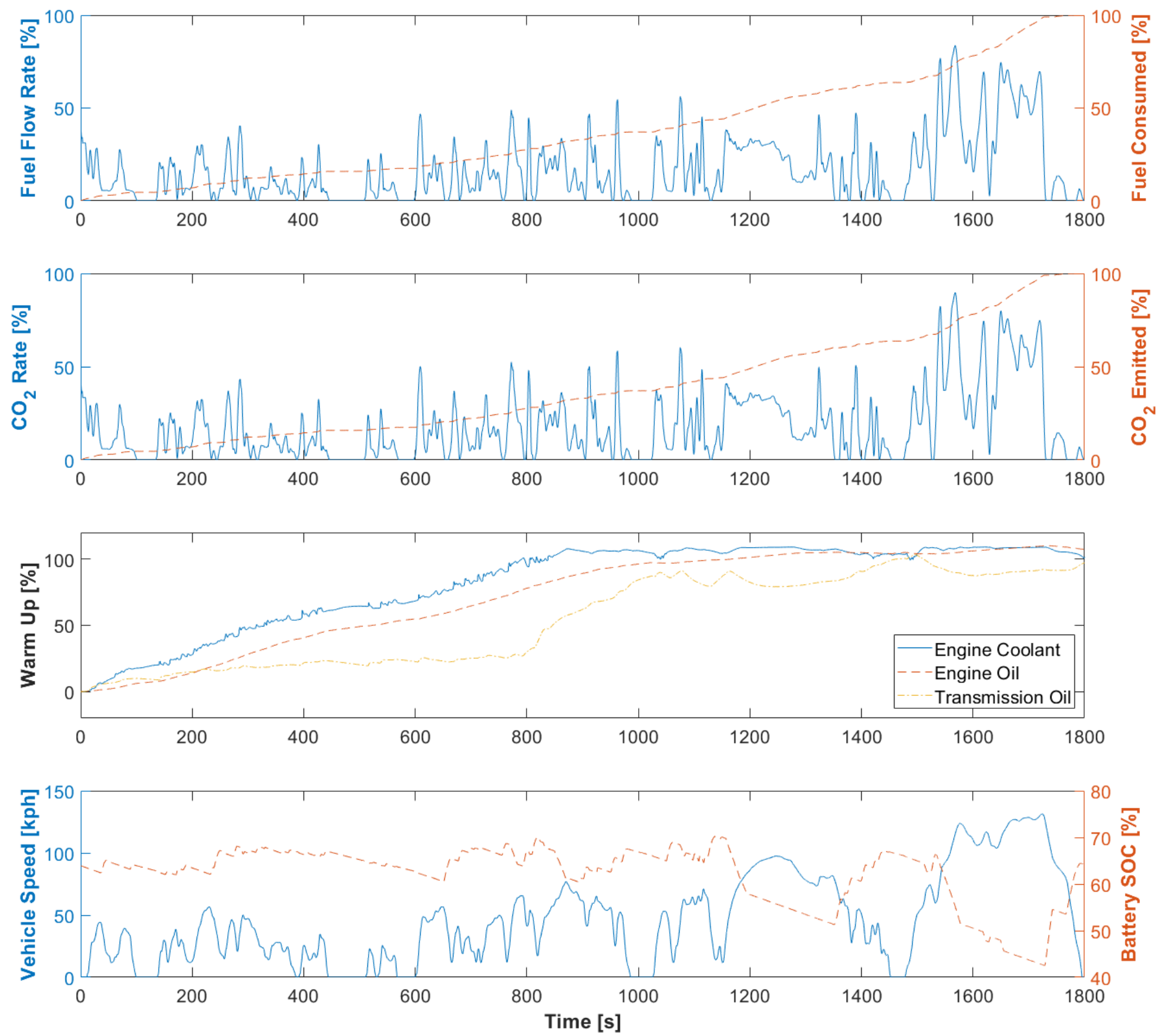

Figure 15 - Standard WLTC at $23^{\circ} \mathrm{C}$. In the upper two plots, the solid line represents the instantaneous consumption/emission respectively (left axis) and the dashed line represents the cumulative result (right axis). In the lower plot, the dashed line respresents the battery SOC (right axis) and the solid line represents the vehicle speed (left axis). Temperatures have been normalized as a between ambient $(0 \%)$ and normal operating temperature $(100 \%)$. 

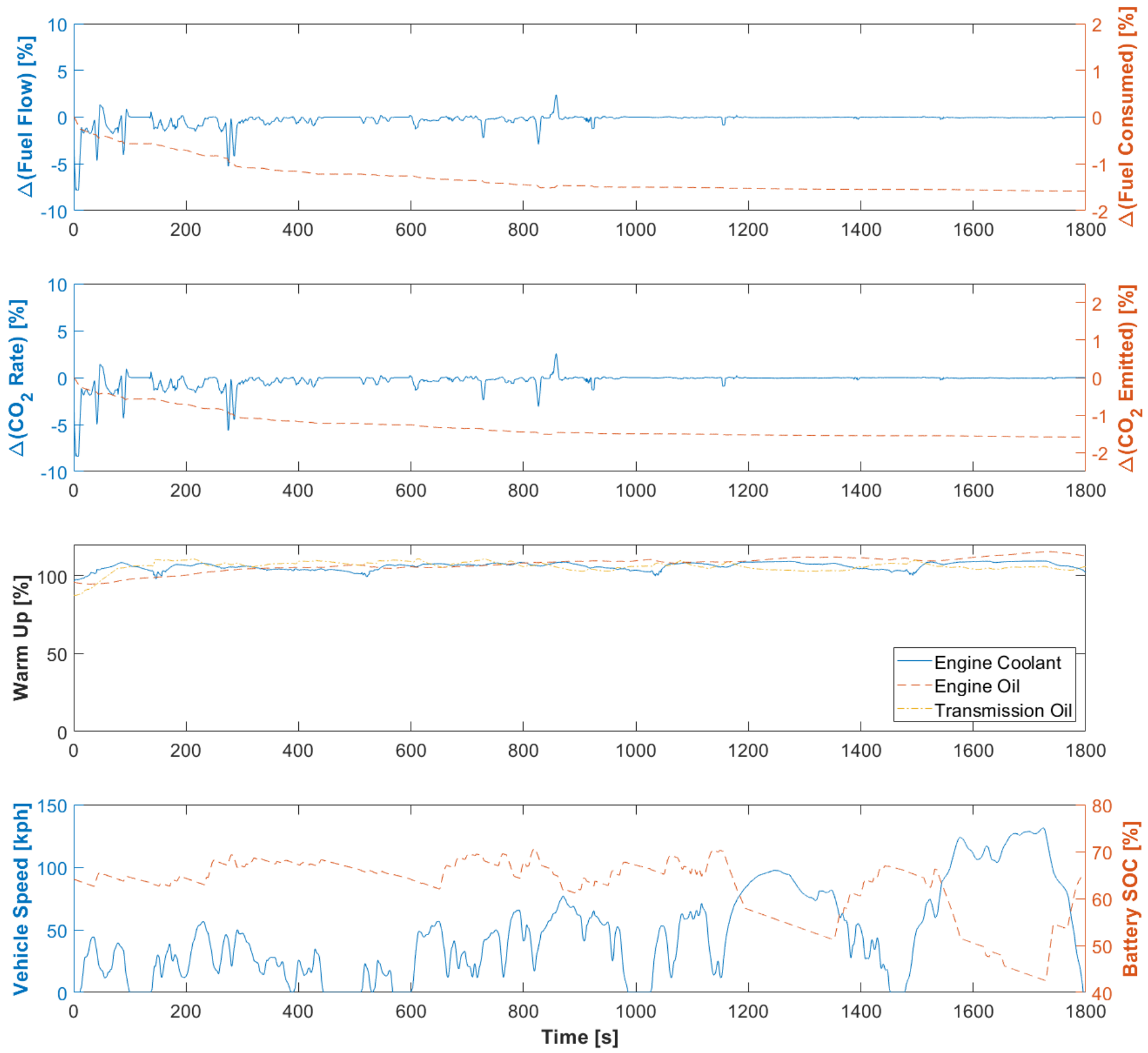

Figure 16 - Simulated WLTP in a $14^{\circ} \mathrm{C}$ ambient environment immediately after pre-conditioning WLTP in a $23^{\circ} \mathrm{C}$ ambient environment (zero soak time). The upper two plots now show the difference in fuel flow rate, fuel consumed and $\mathrm{CO}_{2}$ when compared to the standard WLTC test. Temperatures have been normalized as a between ambient $(0 \%)$ and normal operating temperature $(100 \%)$. 

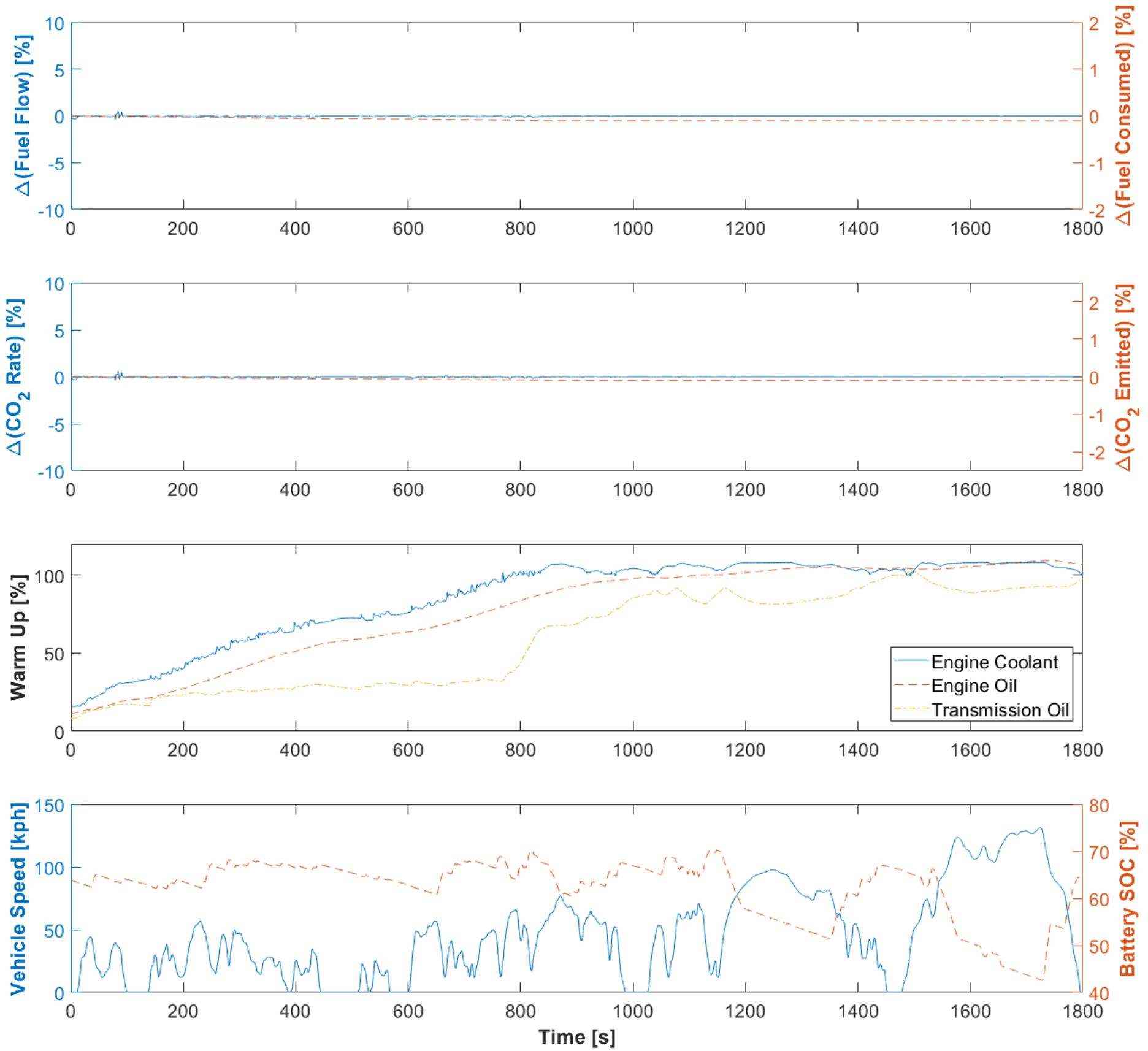

Figure 17 - Simulated Ambient Temperature Correction Test (ATCT) after a 9-hour soak in a $14^{\circ} \mathrm{C}$ ambient environment. The upper two plots now show the difference in fuel flow rate, fuel consumed and $\mathrm{CO}_{2}$ when compared to the standard WLTC test. Temperatures have been normalized as a between ambient $(0 \%)$ and normal operating temperature $(100 \%)$. 